\title{
Arthur Ramos e a rotinização da Antropologia através de seu ensino
}

\author{
Arthur Ramos and the routinization of Anthropology \\ through its teaching
}

\section{Arthur Ramos y la rutinización de la Antropología a través de su enseñanza}

D Amurabi Oliveira ${ }^{1}$

\begin{abstract}
Resumo: Arthur Ramos (1903-1949) foi um dos mais relevantes antropólogos brasileiros do século 20, não apenas devido à sua inestimável contribuição ao debate acerca das culturas afro-brasileiras, como também pelo seu papel no processo de institucionalização da Antropologia no Brasil, com destaque para a fundação em 1941 da Sociedade Brasileira de Antropologia e Etnologia (SBAE). Apesar do crescente interesse pelo seu legado intelectual, os esforços de revisita a seu trabalho pouco têm se dedicado ao processo de rotinização do conhecimento antropológico por ele desempenhado, principalmente a partir de sua atuação na Faculdade Nacional de Filosofia. Proponho-me neste trabalho analisar a rotinização do conhecimento antropológico a partir da atuação de Arthur Ramos como docente, partindo do exame de seus planos de curso, orientações para alunos etc., disponíveis para consulta no acervo da Biblioteca Nacional (BN). Trata-se de uma abordagem sobre a história da Antropologia brasileira que visa compreendê-la a partir de seu ensino, e não simplesmente a partir dos resultados das pesquisas desenvolvidas e das publicações daí resultantes.
\end{abstract}

Palavras-chave: Arthur Ramos. Ensino de Antropologia. Ensino de Ciências Sociais. Antropologia brasileira. Pensamento social brasileiro.

Abstract: Arthur Ramos (1903-1949) was one of the most important Brazilian anthropologists of the 20th century, not only because of his invaluable contribution to the debate about Afro-Brazilian cultures, but also for his role in the process of institutionalizing Anthropology in Brazil, with emphasis on the foundation in 1941 of the Brazilian Society of Anthropology and Ethnology (BSAE). Despite the growing interest in his intellectual legacy, the efforts of revisiting his work have not been devoted to the process of routinizing his anthropological knowledge, mainly from his work at the National Faculty of Philosophy. I propose in this work to analyze the routinization of anthropological knowledge based on the work of Arthur Ramos as a teacher, starting from the examination of his course plans, orientations for students etc., available for

\footnotetext{
${ }^{1}$ Universidade Federal de Santa Catarina (Ufsc, Florianópolis, SC, Brasil). autor.dados_biográficos
} 
consultation in the collection of the National Library (NL). It is an approach on the history of Brazilian anthropology that seeks to understand it from its teaching, and not simply from the results of the researches developed and the resulting publications.

Keywords: Arthur Ramos. Teaching of Anthropology. Teaching Social Sciences. Brazilian Anthropology. Brazilian social thought.

Resumen: Arthur Ramos (1903-1949) fue uno de los antropólogos brasileños más importantes del siglo XX, no solo por su inestimable contribución al debate sobre las culturas afro-brasileñas, sino también por su papel en el proceso de institucionalización de la Antropología en Brasil, con énfasis en la fundación en 1941 de la Sociedad Brasileña de Antropología y Etnología (SBAE). A pesar del creciente interés en su legado intelectual, los esfuerzos por revisar su trabajo no se han dedicado al proceso de rutinización de sus conocimientos antropológicos, principalmente a partir de su trabajo en la Facultad Nacional de Filosofía. En este trabajo, propongo analizar la rutinización del conocimiento antropológico basado en el trabajo de Arthur Ramos como maestro, a partir del examen de los planes de sus cursos, las orientaciones para los estudiantes etc., disponibles para consulta en la colección de la Biblioteca Nacional. Es un enfoque sobre la historia de la Antropología brasileña que busca entenderlo a partir de su enseñanza, y no simplemente a partir de los resultados de las investigaciones desarrolladas y las publicaciones resultantes.

Palabras clave: Arthur Ramos. Enseñanza de la Antropologia. Enseñanza de las Ciencias Sociales. Antropología brasileña. Pensamiento social brasileño.

\section{Introdução}

Arthur Ramos (1903-1949) foi um dos mais proeminentes antropólogos brasileiros da primeira metade do século 20 , cuja vasta produção intelectual versou, sobretudo, sobre as populações afro-brasileiras. Também é bastante conhecido seu papel no processo de institucionalização das Ciências Sociais no Brasil, no qual se destaca a fundação da Sociedade Brasileia de Antropologia e Etnologia, em 1941.

A seu tempo, foi promotor do debate científico no campo das Ciências Sociais através de uma vasta articulação com intelectuais brasileiros e estrangeiros, entre os quais Gilberto Freyre (1900-1987), Anísio Teixeira (1900-1971), Heloísa Alberto Torres (1895-1977), Roger Bastide (1898-1974), Melville Jean Herskovits (1895-1963), Rüdiger Bilden (1893-1980), dentre outros.

Todavia, ainda que tenha havido um crescente interesse por seu legado intelectual (Campos, 2004; Barros, 2008; 2011) esse tem se centrado especialmente em suas pesquisas no campo dos estudos afro-brasileiros, bem como no seu papel na institucionalização das Ciências Sociais junto a sociedades científicas. 
Proponho-me neste trabalho analisar o processo de rotinização ${ }^{1}$ do conhecimento das Ciências Sociais a partir da atuação de Arthur Ramos enquanto professor de Antropologia da Faculdade Nacional de Filosofia (FNF) na Universidade do Brasil (UB), destacando as principais categorias e temas acionados por Ramos em suas atividades docentes, e como elas relevam uma determinada compreensão das Ciências Sociais. Para tal intento, possuo como base empírica de investigação o acervo disponibilizado no Arquivo Arthur Ramos, da Biblioteca Nacional e, em meio à vastidão de valiosos documentos acessíveis aos pesquisadores, volto-me justamente para aqueles que registram à vida ordinária de Ramos como professor.

Refiro-me aqui a três tipos principais de documentos disponibilizados no Arquivo Arthur Ramos que me interessam nessa pesquisa: a) planos de ensino de disciplinas ministradas por ele; b) orientações de alunos; e c) documentos relativos à organização e estruturação da FNF e da UB.

Compreendo assim, que através das categorias acionadas pelo autor, bem como temáticas exploradas em seus planos de ensino, podem revelar elementos importantes do tipo de Antropologia produzida no período, e rotinizada através das cátedras universitárias. Do mesmo modo, nos documentos referentes aos processos de orientação de teses há importantes referências para uma melhor compreensão sobre como Ramos pensava as Ciências Sociais.

Na mesma direção, os documentos referentes à organização acadêmica administrativa da FNF e da Universidade do Brasil indicam uma determinada compreensão do campo acadêmico das Ciências Sociais naquele período, através da estruturação dos cursos, da própria articulação entre as disciplinas, que transpareciam assim um dado entendimento sobre o que seriam as Ciências Sociais, demarcando proximidades e distanciamentos com outros campos disciplinares.

Busco com esse trabalho, portanto, analisar o processo de rotinização das Ciências Sociais, ou mais especificamente da Antropologia, através da prática docente de Arthur Ramos. Levanto como hipótese que apesar de pouco visibilizadas nas pesquisas realizadas na seara da história da Antropologia, as práticas docentes relevam o que havia de mais rotineiro no processo de sistematização e institucionalização das Ciências Sociais.

Acredito assim poder contribuir para a discussão mais ampla no campo da história do ensino da Antropologia ao dar destaque para a relevância das fontes

\footnotetext{
${ }^{1}$ Conceito concebido a partir da ideia de rotinização do carisma em Weber (1999), cujo mesmo sentido atribui Meucci (2011) em seu trabalho acerca dos manuais de Sociologia entre as décadas de 1920 e 1940.
} 
documentais relativas à prática docente, compreendo-as como profundamente relevantes no processo de análise da rotinização do conhecimento científico e institucionalização de uma determinada ciência.

\section{Arthur Ramos em seu tempo}

Nascido em 1903 na cidade de Pilar, interior de Alagoas, Arthur Ramos veio de uma família de médicos. Em 1921 ingressou na Faculdade de Medicina da Bahia, e em 1926 defendeu a tese $O$ primitivo e a loucura, recebendo o título de doutor em Ciências Médicas no mesmo ano. Esta tese utilizava-se amplamente do arsenal da psicanálise através das teorias de Sigmund Freud (1856-1939), e de Lucien Lévy-Bruhl (1987-1939), cujas referências perduram em sua tese de livre-docência intitulada Sordície nos alienados: ensaio de uma psicopatologia da imundice, defendida na mesma faculdade. Atua inicialmente no Serviço Médico Legal do estado da Bahia, onde tem os primeiros contatos com as questões da cultura negra, através do material etnográfico acumulado por Raimundo Nina Rodrigues (1862-1906).

Destaca-se nesse período seu engajamento no processo de divulgação da psicanálise, como podemos observar não apenas por meio de seus textos, como também de sua atuação como redator de periódicos médicos na década de 1930, com destaque para a publicação do número especial de fevereiro de 1934 da Revista Médica da Bahia dedicado exclusivamente ao tema. ${ }^{2}$

Muda-se em 1933 para o Rio de Janeiro, onde assume o cargo de Serviço de Ortofrenia e Higiene Mental a pedido de Anísio Teixeira, que ocupava o cargo de Secretário de Educação na prefeitura do Distrito Federal, ${ }^{3}$ ele permanece à frente do cargo até o ano de 1939, tendo realizado pesquisas junto a escolas experimentais, investigando as causas do desajustamento ao ensino escolar, elaborando o conceito de "criança problema" (Ramos, 1950).

Em 1934 assume, em caráter interino, a cátedra de Psicologia Social na Universidade do Distrito Federal (UDF), mesmo ano em que publica "O negro brasileiro: etnografia religiosa e psicanálise". Resultante do curso de Psicologia Social, Arthur Ramos publica em 1936 o livro Introdução à Psicologia Social.

Ainda que se possa passar a impressão que Arthur Ramos seguia convencionalmente uma carreira mais assentada na área da saúde, entre a

\footnotetext{
${ }^{2}$ Ramos atuava como redator nas seguintes revistas médicas na década de 1930: Bahia Médica, Arquivos do Instituto Nina Rodrigues, Cultura Médica e Revista Médica da Bahia.

${ }^{3}$ Importante marcar que parte significativa das mudanças que vinham sendo implementadas por Anísio Teixeira nesse período vinculam-se às ideias difundidas pela chamada "Escola Nova", de modo que a existência de tal seção representava, justamente, um dos aspectos da modernização no sistema educacional almejado nesse período.
} 
Psicanálise e a Medicina, é válido rememorar dois pontos: a) ainda em seus escritos mais jovens, produzidos na década de 1920, ele já demonstrava um claro interesse pela Antropologia e pelas pesquisas envolvendo as culturas negras; b) a trajetória de médicos antropólogos era relativamente comum nesse período, como demonstra outro caso bastante conhecido, o de René Ribeiro (1914-1990). O fato é que Arthur Ramos passa cada vez mais a se afirmar como antropólogo, o que é realizado de forma articulada com sua própria atuação no campo acadêmico.

A passagem da Psicanálise para a Antropologia ocorre por meio do acionamento de uma série de recursos, uma vez que o mundo acadêmico não é movido apenas pelo conhecimento científico em si mesmo, outros elementos como o prestígio, por exemplo, são profundamente relevantes para compreendermos a dinâmica desse espaço social (Bourdieu, 2011). Devido a tanto, mostra-se fundamental o processo de Ramos afirmar Nina Rodrigues como precursor dos estudos do negro no Brasil, e reivindicar seu lugar como discípulo direto desse. Esse movimento fica ainda mais evidente nos prefácios que escreve para algumas obras de Nina Rodrigues publicadas a partir dos anos de 1935, quando Ramos inicia uma intensa revisão dos trabalhos de seu referido mestre, tais como $O$ animismo fetichista dos negros baianos (1935) e As coletividades anormais (1939), publicações promovidas por Ramos (Campos , 2004).

Sem embargo, Corrêa (2013), questiona esta filiação intelectual alegada por Ramos, uma vez que ele não tomaria a obra de Nina Rodrigues como ponto de partida para suas questões de pesquisa. Apesar de reivindicar o pioneirismo de Nina Rodrigues, Ramos acaba por incorporar outras versões sobre o tema. Ainda segundo Corrêa (2013, p. 219):

[...] o que parece ter ocorrido com a vertente antropológica da escola Nina Rodrigues, representada quase que exclusivamente pelo trabalho de um só autor, foi a utilização de partes de uma obra mais extensa, desvinculada de seu contexto, para conferir uma identidade com profundidade ao trabalho principalmente de Arthur Ramos, distinguindo-o do de Gilberto Freyre.

O fato é que o movimento de aproximação e distanciamento com a obra de Nina Rodrigues é algo fundamental para compreendermos a constituição da identidade de antropólogo de Arthur Ramos, não à toa, ele atribui ao médico-antropólogo maranhense o pioneirismo também no uso da categoria de aculturação (Ramos, 1942), esta também central para os desenvolvimentos posteriores de seu trabalho. 
Sua constituição e afirmação como antropólogo envolvem também seus intensos contatos intelectuais com instituições acadêmicas ${ }^{4}$ e proeminentes pesquisadores estrangeiros, destacando-se a influência culturalista sobre seus trabalhos, especialmente em sua segunda fase, que culmina com a publicação de Introdução à Antropologia brasileira, ainda que inúmeras referências presentes em seus primeiros trabalhos perdurem naqueles desenvolvidos posteriormente (Motta, 2011).

Buscarei a partir desse ponto explorar a rotinização do conhecimento antropológico em Arthur Ramos a partir de sua prática como professor de Antropologia, o que será elaborado principalmente a partir de seus cursos e orientações de alunos, buscando captar com isso, qual concepção de Antropologia que estava em jogo nesse processo.

\section{O professor Arthur Ramos}

Se quisermos compreender melhor o papel de Arthur Ramos no processo de institucionalização da Antropologia brasileira devemos recorrer a sua atuação como professor de Antropologia e Etnografia, o que ocorre a partir de 1939 com sua nomeação como docente interino junto à Faculdade Nacional de Filosofia. Como destaca Barros (2008, p. 66): "Sua concepção de Antropologia se cristaliza na organização da cadeira criada na Faculdade Nacional de Filosofia. Estrutura currículo, programas, cria o 'Gabinete de Antropologia', organiza provas, cursos de aperfeiçoamento e de doutorado".

Quando Arthur Ramos assume a cátedra de Antropologia e Etnografia do Brasil o projeto da UDF estava se exaurindo, de modo que ela foi dissolvida e seus quadros, incluindo professores e alunos, incorporados à FNF da UB.

Em meio a este processo, Fávero (1989) em uma análise cuidadosa dos quadros da FNF indica o forte clientelismo que era praticado nas contratações docentes, bem como as intensas disputas ideológicas que envolviam esse processo. Para Miceli (1989), a proximidade com o estado nos termos em que ocorriam nesta instituição era um impeditivo para que as Ciências Sociais pudessem ser plenamente autônomas. Segundo o autor:

$\mathrm{Na}$ então capital federal do país e centro das lutas envolvendo as diversas facções de jovens intelectuais radicalizados no pós-30, praticamente todas as iniciativas de "construção institucional" que

\footnotetext{
${ }^{4}$ Entre os documentos referentes a este assunto no acervo da Biblioteca Nacional encontramos a sua indicação enquanto membro honorário da Associação de Pesquisa em Antropologia, da Northwestern University em 1941, Amigo Estrangeiro da Associação de Antropologia Americana em 1948. E ainda referências ao período em que ministrou os cursos de Raças e Culturas do Brasil e Contatos de Raças e Culturas, na Universidade de Louisiana em 1940.
} 
repercutiram de pronto e a longo prazo sobre as Ciências Sociais foram caudatárias dos recursos estatais e dos projetos políticos de lideranças emergentes no interior da máquina governamental (Miceli, 1989, p. 94).

Um exemplo disso percebe-se quando Raul Leitão da Cunha (18811947), então Reitor da Universidade do Brasil, chega a escrever uma carta ao ministro Gustavo Capanema (1900-1985) indicando 45 nomes de possíveis professores para a universidade, e no caso da disciplina de Antropologia e Etnografia ele indicou o nome de José Augusto Padberg Drenkpol. ${ }^{5}$ Os critérios de seleção de professores, portanto, pareciam estar fortemente vinculados às relações pessoais e ao poder local, ainda que não desapareçam completamente os critérios acadêmicos.

O fato é que as contratações na FNF sempre foram continuamente polêmicas, houve inúmeras listas com indicações de nomes enviadas para o ministro da Educação, algumas com informações complementares. Lúcia M. L. Oliveira (1995) faz referência a uma lista na qual há a indicação do nome de Arthur Ramos para a cadeira de Psicologia, bem como para a de Antropologia, nesse último caso com indicação de Heloisa Alberto Torres, que atuava na seção de Antropologia no Museu Nacional, e exercia neste momento o cargo de diretora. É importante de se ressaltar que na mesma lista constam outros nomes para a área de Antropologia, também indicados pela antropóloga do Museu Nacional.

Muitos daqueles que constavam em inúmeras listas não foram contratados, como Oliveira Vianna (1883-1951) que contava com um substancial prestígio intelectual, todavia, o nome de Ramos perdurou e ele se tornou professor interino.

No Arquivo Arthur Ramos encontra-se a forma como sua carga horária era distribuída. Nos cursos de Geografia e História ele lecionava a cátedra de Antropologia nas segundas e sextas, entre $14 \mathrm{~h}$ e $15 \mathrm{~h}$, de Etnografia nas quartas e sábados também entre 14h e 15h, e de Etnografia do Brasil nas terças das $14 \mathrm{~h}$ às $15 \mathrm{~h}$ e no sábado das $15 \mathrm{~h}$ às $16 \mathrm{~h}$. No curso de Ciências Sociais ele lecionava a cátedra de Antropologia e Etnografia nas segundas, quartas, sextas e sábados. E para cada orientando de doutorado ele dedicava uma hora por semana, havendo seis inscritos até a data de 27 de março de 1942. Segundo os dados disponíveis, ele teria 29 horas semanais de atividades docentes na FNF.

\footnotetext{
${ }^{5}$ Era formado em Ciências Naturais pela Universidade de Munique e Friburgo na Alemanha, prestou concurso em 1925 para o cargo de professor substituto da seção de Antropologia e Etnografia do Museu Nacional. Tendo ficado em segundo lugar, tornando-se auxiliar de seção e, posteriormente, professor interino da cátedra de Estratigrafia e Paleontologia (Keuller, 2008).
} 
É importante lembrar também que o processo de delimitação disciplinar nesse momento ainda é bastante incipiente, e o próprio curso de Ciências Sociais inicialmente quando criado na UDF poderia oferecer a seus alunos tanto a habilitação do bacharelado quanto da formação de professor, com menção em Sociologia, História ou Geografia (Meucci, 2015). Desse modo, o trânsito de Arthur Ramos pelos cursos de Geografia, História e Ciências Sociais indica diferentes possibilidades de interface que a Antropologia realizava naquele momento em termos institucionais. Ademais, na passagem da UDF para a UB houve mudanças nos cursos de História e Geografia, naquele momento estavam organizados como um só.

Encontram-se no acervo Arthur Ramos seus planos de curso de Antropologia e Etnografia, Antropologia e Etnografia do Brasil. Todos eram programas extensos, os dois primeiros possuíam dez pontos, com subdivisões, e o terceiro vinte pontos sem subtópicos. Chama a atenção o fato de que todo o tempo há uma intensa articulação entre a Antropologia Cultural e a Antropologia Física, sempre acompanhada de uma busca pela diferenciação entre as duas, ${ }^{6}$ de modo que categorias como "raças" e "tipos étnicos" constam amiúde em seus planos. $\mathrm{O}$ curso envolvia exames intermediários, bem como provas de caráter oral, normalmente os pontos indicados como de prova são os mesmos indicados no plano de curso.

Merece destaque o fato de que o terceiro ponto do curso de Etnografia Brasileira era Estudos sobre o negro: a escola de Nina Rodrigues. Este talvez seja um dos pontos centrais para a compreensão da posição de Arthur Ramos no processo de institucionalização da Antropologia brasileira a partir de sua prática docente, pois, encontramos aí ao menos duas questões relevantes: a sobreposição dos estudos do negro aos estudos das relações raciais, bem como, a redução desses estudos no Brasil à escola Nina Rodrigues.

É na cátedra, no espaço institucional de rotinização do conhecimento antropológico, que Arthur Ramos encontra a possibilidade de reafirmar suas convicções intelectuais e sua concepção de antropologia, reforçando a relevância dos estudos sobre o negro para a compreensão do Brasil ${ }^{7}$, e

\footnotetext{
${ }^{6}$ Esse era o primeiro ponto de seu plano de disciplina para o 3o ano do curso de Ciências Sociais. Meucci (2015) chega a apontar que haveria certa tensão entre Freyre e Ramos nas diversas modalidades de Antropologia praticadas por ambos, ainda que se possa destacar que em vários momentos Freyre afirme que Ramos tomou conhecimento dos trabalhos de Boas, Kroeber e Herskovits através dele (Freyre, 1968).

${ }^{7}$ Importante perceber que Arthur Ramos estava profundamente engajado em determinadas disputas acadêmicas de seu tempo, e assim como outros intelectuais - tais como Edson Carneiro (1912-1972) - estava profundamente preocupado em realizar um deslocamento ênfase dos estudos das relações raciais para os "estudos sobre o negro" (Corrêa, 1999).
} 
centralizando tais estudos em uma única escola, da qual ele se considera o grande legatário, ainda que isso possa ser questionado, como indica Corrêa (2013).

Ainda que os estudos sobre as populações indígenas também ganhem destaque em seus programas, é apenas no ponto sobre os estudos sobre o negro que há uma delimitação teórica claramente posta. No curso de Etnografia brasileira dos 20 pontos a serem lecionados, além do já referido acerca dos Estudos sobre o negro, outros sete pontos cobriam estudos sobre populações africanas, além de um sobre folclore de influência negra. Os contos populares, e sobre as festas populares de origem Ioruba.

Nos cursos para as Ciências Sociais a disciplina deixa de ser predominantemente temática e passa a ser mais teórica, havendo explanações sobre o método evolucionista da cultura, o método histórico-cultural, o método funcionalista, os métodos norte-americanos da cultura, ainda que só ao método evolucionista caiba também um tópico específico voltado para sua crítica. Essa mudança de uma abordagem temática para uma mais teórica talvez reflita como que Arthur Ramos compreendia o papel da Antropologia nesses diversos cursos, havendo um papel mais estrutural no de Ciências Sociais, ainda que no total houvesse uma carga horária semelhante dessas disciplinas nos dois cursos.

Apesar de termos hoje uma compreensão de que a Antropologia constitui um dos eixos centrais do curso de Ciências Sociais, é importante destacar que naquele momento as divisões disciplinares estavam postas ainda de forma tênue, e a própria compreensão sobre o que seriam tais ciências estava colocado de forma distinta do que temos hoje.

Usando da prerrogativa de que de no documento que designa a finalidade da FNF (Decreto Lei n. 1.190, de 4 de abril de 1939) indica que esta deveria oferecer cursos ordinários e também cursos extraordinários, podendo ser esses cursos de aperfeiçoamento ou cursos avulsos, Ramos escreve ao reitor solicitando a criação do Curso de Aperfeiçoamento em Antropologia e Etnografia, além de apresentar esta demanda como algo que se origina na procura dos próprios alunos, e na necessidade de desenvolvimento da vida científica nacional, ele reforça a necessidade de realização de pesquisas originais, o que garantiria a autonomia didática da cadeira, caso contrário ela seria relegada apenas à condição de cadeira assessória nos cursos de Ciências Sociais e de Geografia e História.

O curso de Geografia e História encontrava-se organizado da seguinte forma: primeiro ano com as disciplinas de Geografia física, Geografia humana, Antropologia, História da antiguidade e da idade média; segundo ano com 
as de Geografia física, Geografia humana, História moderna, História do Brasil, Etnografia, e terceiro ano com as de Geografia do Brasil, História contemporânea, História do Brasil, História da América, Etnografia do Brasil. Ao passo em que o curso de Ciências Sociais organizava-se curricularmente da seguinte forma: primeiro ano com as disciplinas de Complementos de matemática, Sociologia, Economia política, História da filosofia; segundo ano com as de Estatística geral, Sociologia, Economia política, Ética, e terceiro ano com as de Sociologia, História das doutrinas econômicas, Política, Antropologia e etnografia, Estatística aplicada.

Considerando a organização curricular, parece fazer sentido o diagnóstico apontado por Ramos na justificativa de criação do Curso de Aperfeiçoamento em Antropologia e Etnografia. ${ }^{8}$ Ainda nos termos do mesmo decreto no parágrafo único do artigo 48 há a indicação de que "Será conferido o diploma de doutor ao bacharel que defender tese original de notável valor; depois de dois anos pelo menos de estudos, sob a orientação do professor catedrático da disciplina sobre que versar o trabalho" (Decreto Lei n. 1.190, de 4 de abril de 1939), neste caso o curso de aperfeiçoamento possibilitava também a formação de uma primeira geração de doutores em Antropologia formados pela UB.

Havia claramente em Arthur Ramos a ideia de produzir um corpo de profissionais no campo da Antropologia, não à toa, parte de tais orientações eram resultantes do curso de aperfeiçoamento em Antropologia e Etnografia, proposto por Ramos ao reitor em 1939, cuja primeira turma ingressou em 1940, havendo o registro da formação ao menos de duas turmas em 1941 e em 1942. Essa geração de antropólogos profissionais teria a marca da Antropologia concebida por ramos, o que se materializava através dos cursos de Antropologia ofertados na FNF e das orientações dadas.

Creio que a parte mais interessante dos documentos aqui acessados talvez seja aquela referente às orientações de Arthur Ramos a seus alunos. Encontrase no seu acervo anotações para os seguintes alunos: Hildegard Sternberg, Ary Rodrigues da Matta, Regina Freire Carvalhal, Sara Coleber, Marina Vasconcello, Maria Dantas de Carvalho, Irene da Silva de Melo Carvalho, Armando Sampaio de Souza, Antônio Traverso.

Suas orientações eram divididas em três partes: cursos sugeridos, pesquisas e bibliografia. No geral os cursos indicados eram aqueles oferecidos pela própria FNF, mas também pontualmente havia a indicação de cursos a serem realizados na Faculdade Nacional de Medicina, e no Instituto Nacional

\footnotetext{
${ }_{8}^{8}$ Além do curso de aperfeiçoamento, para garantir maior autonomia didática a sua disciplina, Ramos propõe também a criação de um gabinete de Antropologia.
} 
de Música. Ganha destaque a indicação do seminário de Aculturação oferecido pelo curso de Doutorado da FNF, esse fora indicado para sete alunos sob sua orientação.

Interessante perceber aí que a questão da aculturação, especialmente da aculturação negra foi uma preocupação constante na obra deste antropólogo, compreendido como mudanças nos padrões originais de cultura de um ou mais grupos após o contato contínuo destes (Ramos, 1942). Também recorrentemente Arthur Ramos indicava a seus alunos a realização de cursos dos quais ele mesmo era professor, como os de Antropologia e de Etnografia Brasileira, ainda que em alguns casos apenas parte do curso fosse indicado para a tese.

No que tange às indicações de pesquisas ele tendia a valorizar, por um lado, as pesquisas em arquivos, e por outro o trabalho de campo, normalmente demandando viagens por parte dos alunos. Penso que essa também era uma forma de Arthur Ramos ter acesso a um material mais amplo sobre temas que o interessavam, uma vez que a rotina de professor universitário limitava suas possibilidades de realizar contínuos trabalhos de campo. Em seus documentos encontra-se referência a suas viagens de campo, sempre fazendo a ressalva de que não atrapalhariam as aulas, de modo que, aparentemente, a maior parte de seu trabalho de campo era realizada no período do recesso escolar.

A seus orientandos raramente indicava livros ou autores específicos, indicava temáticas que deveriam ser exploradas nas leituras de seus alunos, o que deveria ser acompanhado algumas vezes por fichas de leituras. Uma exceção é a orientação a Ary Rodrigues da Matta, que pesquisava as populações primitivas do Brasil, tendo sido indicada a leitura de Jehrbuch der Anthropologie de R. Martin, e de Traité d'anatomie humaine de L. Testut.

Interessante notar que em meio a essas orientações encontramos o nome de Mariana de Vasconcellos, que veio a se tornar sua assistente e posteriormente sucessora na cátedra de Antropologia e Etnografia (Ribeiro, 2008), de modo que, de fato, o curso acaba cumprindo uma de suas finalidades, de recrutar assistentes para a cátedra. Seu tema de tese era "A revolta dos malês na Bahia, e sua interpretação contra aculturativa”, para a qual Arthur Ramos indicou a participação no seminário de aculturação do curso de Doutorado, parte do curso de etnografia do Brasil referente ao negro e curso de árabe, além de pesquisas em arquivos, com destaque para o Arquivo Público de São Paulo e de São Salvador.

Sua consolidação enquanto docente deu-se em 1945 quando realizou o concurso para professor catedrático. Sua banca fora constituída por José Farias Goés Sobrinho, Emílio Willems, Alvaro Froes da Fonseca, José Basto D’Ávila 
e Heloisa Alberto Torres, à qual foi apresentada a tese $A$ organização dual entre os índios brasileiros. Nem todos os membros eram exatamente versados em Antropologia, e certamente o currículo do candidato era intimidador, uma vez que constava mais de mil publicações, entre livros, artigos em periódicos, jornais, resenhas e conferências, além de filiação a associações científicas internacionais, experiência como professor visitante nos Estados Unidos etc. ${ }^{9}$ Sem embargo, segundo Barros (2008, p. 173):

Depoimentos da época se referem ao mal-estar que envolveu o concurso. Atendo-se a um detalhe de erro de tradução de um termo em inglês, a examinadora criticou severamente o candidato, embora este, alegando que o equívoco fora causado pela datilógrafa, avocasse o testemunho dos colegas de que falava, lia e escrevia francês, inglês e alemão, desde os tempos de estudante.

Para alguns, parte do que ocorreu seria explicado como resultante de certa perseguição realizada por Heloisa Alberto Torres a Arthur Ramos. Isso poderia ainda refletir certa rixa entre as distintas instituições formativas, a FNF e o Museu Nacional, uma vez que para Arthur Ramos em algumas publicações teria deixado claro que à FNF caberia a formação de profissionais de nível superior em Antropologia, e ao Museu Nacional a formação de técnicos. Como indica Corrêa (1997, p. 28):

O conflito expresso por aquela anedota vai assim muito além de um mero "facciosismo" entre duas instituições - uma de ensino, outra de pesquisa - e mostra que as relações tensas entre a diretora do Museu e o catedrático da Faculdade de Filosofia definiam também os termos de uma disputa interna ao campo da disciplina: seu objeto, seu método de pesquisa e sua "identidade social", isto é, o sítio institucional da nova disciplina.

Esses conflitos tornaram-se mais evidentes quando Ramos é convidado, em 1949, para assumir o departamento de Ciências Sociais da Unesco em Paris. Assim, instaura-se uma disputa entre Heloisa Alberto Torres e Marina de Vasconcellos para assumirem interinamente a cátedra de Antropologia e Etnografia, que acaba por ficar ao encargo desta última. Heloisa Alberto Torres tem seu pedido de inscrição indeferido, uma vez que, apesar do reconhecimento de notório saber, não possuía o requisito posto no artigo no 98 do Regimento

\footnotetext{
${ }^{9} \mathrm{O}$ currículo apresentado no concurso e o comprovante de inscrição encontram-se disponíveis para consulta, no Arquivo Arthur Ramos.
} 
da FNF, que demandava a apresentação de curso superior, cujo currículo contivesse disciplina correspondente à cátedra posta em concurso.

Tais disputas, no entanto, não ofuscam o fato de que Heloisa Alberto Torres e Arthur Ramos cooperaram em diversos projetos intelectuais, que se vinculam ao processo de institucionalização da Antropologia no Brasil. Nesse sentido, destaca-se que o papel de Arthur Ramos no processo de institucionalização da Antropologia brasileira não se limitou a sua atuação como docente, pois também foi fundador da primeira sociedade científica da área no Brasil, uma das primeiras do mundo, a Sociedade Brasileira de Antropologia e Etnologia, em $1941^{10}$, desse modo, percebe-se que suas preocupações com a Antropologia iam para além da atuação local, o que pode ser percebido também pela intensa troca de correspondências com intelectuais diversos, assim como com distintas associações científicas. ${ }^{11}$

\section{Considerações finais}

Ainda que explorado de forma bastante breve, buscou-se visibilizar como as práticas docentes transparecem o movimento de rotinização de uma ciência, e mais que isso, uma determinada concepção de ciência.

No caso de Arthur Ramos o fato dele ser o mais proeminente antropólogo de seu período vinculado a uma instituição de ensino tem peso significativo na hipótese aqui levantada, uma vez que sua prática estava diretamente vinculada às disputadas acadêmicas mais amplas vivenciadas pela Antropologia brasileira naquele momento. Seu movimento de institucionalização da Antropologia através do ensino e da pesquisa aponta para a relevância que ele percebia no processo de docência para a consolidação da Antropologia no Brasil.

Através de seus planos de curso, bem como de suas orientações, pode-se observar suas vinculações teóricas, e as tentativas de torná-las hegemônicas em um dado contexto intelectual. Nesse conjunto destaca-se a busca pela centralidade dos estudos do negro em oposição aos estudos das relações raciais, e a relevância da escola Nina Rodrigues nesse processo, o que desembocava em sua própria relevância. Também cabe o destaque à perspectiva culturalista e ao conceito de aculturação, que parece mostrou-se como chave para Ramos compreender desde a Antropologia o movimento mais amplo da sociedade brasileira.

\footnotetext{
${ }^{10}$ Para uma melhor análise vide Azeredo (1986).

${ }^{11}$ Além da filiação do próprio Arthur Ramos a diversas sociedades científicas internacionais, encontra-se disponível em sua documentação o recibo de pagamento da anuidade da InterAmerican Society of Anthropology and Geography, o que indica a busca por uma inserção mais ampla da sociedade científica brasileira por ele fundada em outros espaços acadêmicos.
} 
Seus investimentos na criação dos cursos de aperfeiçoamento de Antropologia, na preocupação em ter uma continuadora de seu trabalho na cátedra de Antropologia e Etnografia, demonstram quão central ele percebia a Antropologia. Finalizo aqui este trabalho destacando a fala do próprio Ramos no texto "Os grandes problemas da antropologia brasileira":

A Universidade do Brasil, tão pomposa no seu título ambicioso, não possui ainda um Instituto de Antropologia, tão reclamado e tão necessário. $\mathrm{O}$ ensino das várias disciplinas que constituem a ciência do homem se acha distribuído pelos currículos de geografia, da história ou da sociologia, nos quais é considerado material subsidiário ou ilustrativo. O estudante passa pelos cursos de Antropologia, num contato rápido e obrigatório que o habilita apenas a completar os seus cursos de geografia ou história que o conduzem ao professorado secundário. E como não há Antropologia nos currículos secundários, como não há aproveitamento de técnicos em Antropologia nas várias instituições que poderiam recrutá-los, o ensino da Antropologia nas Escolas Superiores não encontra uma finalidade imediata ou pragmática (Ramos, 2015, p. 211-212).

Pensar o lugar da Antropologia no mundo é pensar também o lugar de seu ensino, seja na universidade, seja em outros espaços. Arthur Ramos a seu tempo e a seu modo engajou-se ativamente no processo de afirmação da Antropologia como campo disciplinar próprio, cuja articulação se dava a partir da cátedra, espaço fundamental para a rotinização do conhecimento e para a formação de novos quadros, ainda que nunca tenha se limitado a ela na compreensão de seu lugar de atuação como antropólogo.

\section{Referências}

ARQUIVO, Arthur Ramos. Rio de Janeiro: Fundação Biblioteca Nacional, 2004.

AZEREDO, Paulo Roberto. Antropólogos e pioneiros: a história da Sociedade Brasileira de Antropologia e Etnologia. São Paulo: Edusp, 1986.

BARROS, Luitgarde Oliveira Cavalcanti (org.). Arthur Ramos. Rio de Janeiro: Fundação Miguel de Cervantes, 2011.

BARROS, Luitgarde Oliveira Cavalcanti (org.). Arthur Ramos e as dinâmicas sociais de seu tempo. Maceió: Edufal, 2008.

BOURDIEU, Pierre. Homo academicus. Florianópolis: Edufsc, 2011.

CAMPOS, Maria José. Arthur Ramos: luz e sombra na antropologia brasileira. Rio de Janeiro: Edições Biblioteca Nacional, 2004. 
CORRÊA, Mariza. Cartas marcadas: Arthur Ramos e o campo das relações raciais no final dos anos trinta. Anais da Biblioteca Nacional, Rio de Janeiro, n. 119, p. 35-58, 1999.

CORRÊA, Mariza. Dona Heloisa e a pesquisa de campo. Revista de Antropologia, São Paulo, v. 40, n. 1, p. 11-54, 1997. Disponível em: https://doi.org/10.1590/S003477011997000100002. Acesso em: 22 out. 2019.

CORRÊA, Mariza. Ilusões de liberdade: a escola Nina Rodrigues e a antropologia no Brasil. Rio de Janeiro: Fiocruz, 2013. https://doi.org/10.7476/978857541 5696

FÁVERO, Maria de Lourdes. Faculdade Nacional de Filosofia: o corpo docente matizes de uma proposta autoritária. Rio de Janeiro: UFRJ, 1989.

FREYRE, Gilberto. Como e porque sou e não sou sociólogo. Brasília: UnB, 1968.

KEULLER, Adriana Tavares do Amaral Martins. Os estudos físicos de antropologia no Museu Nacional do Rio de Janeiro: cientistas, objetos, ideias e instrumentos (18761939). 2008. Tese (Doutorado em Ciências) - Programa de Pós-Graduação em História Social, Departamento de História, Faculdade de Filosofia, Letras e Ciências Humanas, Universidade de São Paulo, São Paulo, 2008. https://doi.org/10.11606/t.8.2008.tde18092008-161852

MEUCCI, Simone. Artesania da Sociologia no Brasil: contribuições e interpretações de Gilberto Freyre. Curitiba: Appris, 2015.

MEUCCI, Simone. Institucionalização da sociologia no Brasil: primeiros manuais e cursos. São Paulo: Hucitec, 2011.

MICELI, Sergio. Condicionantes do desenvolvimento das ciências sociais. In: MICELI, Sérgio (org.). História das ciências sociais no Brasil. São Paulo: Vértice, 1989. v. 1, p.72-110. https://doi.org/10.11606/issn.2316-9141.v0i169 p421-426

MOTTA, Roberto. Arthur Ramos, sincretismo e mentalidade pré-lógica em O negro brasileiro. In: BARROS, Luitgarde Oliveira Cavalcanti (org.). Arthur Ramos. Rio de Janeiro: Fundação Miguel de Cervantes, 2011. p.30-80.

OLIVEIRA, Lúcia Maria Lippi. As ciências sociais no Rio de Janeiro. In: MICELI, Sérgio (org.). História das ciências sociais no Brasil. São Paulo: Sumaré, 1995. v. 2, p. 233-307.

RAMOS, Arthur. A aculturação negra no Brasil. Rio de Janeiro: Companhia Editora Nacional, 1942.

RAMOS, Arthur. A criança problema. São Paulo: Casa do Estudante do Brasil, 1950. 
RAMOS, Arthur. Os grandes problemas da antropologia brasileira. Mana, Rio de Janeiro, v. 21, n. 1, p. 195-212, 2015. Disponível em: http://dx.doi.org/10.1590/010493132015v21n1p195. Acesso em: 22 out. 2019.

RIBEIRO, Adélia Maria Miglievich. Marina de Vasconcellos e as ciências sociais cariocas: a perspectiva dos círculos sociais. História, Ciências, Saúde-Manguinhos, Rio de Janeiro, v. 15, p. 17-41, 2008. Disponível em: http://dx.doi.org/10.1590/S010459702008000500002 . Acesso em: 22 out. 2019.

WEBER, Max. Economia e sociedade. Brasília: UnB, 1999. v. 1.

Recebido em: 6/9/2017.

Aprovado em: 20/6/2019.

Publicado em: 15/12/2019.

Autor correspondente:

Amurabi Oliveira

Universidade Federal de Santa Catarina

Departamento de Sociologia e Ciência Política

Rua Eng. Agronômico Andrey Cristian Ferreira, s/n

88040-900, Florianópolis, SC, Brasil

Amurabi Oliveira <amurabi_cs@hotmail.com>

Doutor em Sociologia pela Universidade Federal de Pernambuco (UFPE, Recife, PE, Brasil). Professor do departamento de Sociologia e Ciência Política da Universidade Federal de Santa Catarina (Ufsc, Florianópolis, SC, Brasil). Pesquisador do CNPq.

Orcid: https://orcid.org/0000-0002-7856-1196 